\title{
Cooling of High-Power LED Lamp Using a Commercial Paraffin Wax
}

\author{
J. Zmywaczyk ${ }^{1}$ - P. Zbińkowski ${ }^{1}$ - H. Smogór ${ }^{2}$. \\ A. Olejnik ${ }^{1}$ - P. Koniorczyk ${ }^{1}$
}

Received: 20 June 2016 / Accepted: 4 January 2017 / Published online: 13 January 2017 (C) The Author(s) 2017. This article is published with open access at Springerlink.com

\begin{abstract}
Commercial paraffin wax used by Bolsius Nederland B.V. for manufacturing various kinds of candles was applied as a phase-change material (PCM) for cooling a $28 \mathrm{~W}$ high-power light emitting diode (LED) panel during its operation. The main problem arising during operation of an LED is thermal management. According to the manufacturer's datasheet specifications (BioSolution Ltd. www.biosolution. $\mathrm{pl})$, the operating temperature range for the LED street lamp UL28W is $\left(-30^{\circ} \mathrm{C}\right)$ to $\left(+40^{\circ} \mathrm{C}\right)$. The object of the present study was an LED panel containing 28 pieces of high-power 1W LEDs connected in series (4 LEDs in each of the 7 rows) mounted on an aluminum plate of dimensions $80 \mathrm{~mm}$ by $135 \mathrm{~mm}$. The tested aluminum plate was placed in a block made of aluminum with a hollow compartment containing Bolsius paraffin wax of density $914 \mathrm{~kg} \cdot \mathrm{m}^{-3}$ at room temperature. Temperatures were recorded using K-type thermocouples at selected locations of the tested LED panel for several values of the power supplied to it, while utilizing PCM and without it. As the manufacturer of Bolsius wax candles does not provide any data on the thermal properties of the material used, it was necessary to carry out micro-calorimetric research. Thermophysical properties of the paraffin wax such as the apparent specific heat, enthalpy of phase transition and temperature of phase change transition during heating and cooling were determined using the Netzsch DSC 214 Polyma. The Netzsch TG 209F3 Tarsus was used for TG/DTG measurements. DSC investigations revealed the following thermal transitions taking place during the first heating: solid-solid transition (onset
\end{abstract}

Selected Papers of the 13th International Symposium on Temperature, Humidity, Moisture and Thermal Measurements in Industry and Science.

\footnotetext{
$凶 \quad$ J. Zmywaczyk

janusz.zmywaczyk@wat.edu.pl

1 Military University of Technology, Warsaw, Poland

2 Application Laboratory Netzsch Instruments Ltd, Cracow, Poland
} 
$30.4^{\circ} \mathrm{C}$, peak at $40.9^{\circ} \mathrm{C}$ ), solid-liquid transition (onset $47.7^{\circ} \mathrm{C}$, peak at $54.9^{\circ} \mathrm{C}$, end at $58.3^{\circ} \mathrm{C}$ ), latent heat of energy storage $201 \mathrm{~J} \cdot \mathrm{g}^{-1}$, apparent specific heat corresponding to peak at $41.5^{\circ} \mathrm{C}\left(5.498 \mathrm{~J} \cdot \mathrm{g}^{-1} \cdot \mathrm{K}^{-1}\right)$. DTG investigations revealed that the decomposition of paraffin wax is a two-step process. At $283^{\circ} \mathrm{C}$ there was observed a slightly slower decomposition $\left(9.43 \% \cdot \mathrm{min}^{-1}\right)$ than that at $323{ }^{\circ} \mathrm{C}\left(12.5 \% \cdot \mathrm{min}^{-1}\right)$. The experimental results obtained upon cooling the high-power LED lamp during its operation can be applied to verify results of numerical modeling of the heat transfer problems with phase-change transitions. An attempt at modeling such a problem based on 1D fixed grid with variable time step approach was undertaken in this work.

Keywords LED cooling · Paraffin wax · Phase change material · Thermophysical properties

\section{Nomenclature}

\section{Latin}

$c_{p} \quad$ Specific heat under constant pressure $\left(\mathrm{J} \cdot \mathrm{g}^{-1} \cdot \mathrm{K}^{-1}\right)$

E Illuminance (1x)

$k \quad$ Thermal conductivity $\left(\mathrm{W} \cdot \mathrm{m}^{-1} \cdot \mathrm{K}^{-1}\right)$

$L \quad$ Latent heat of fusion per unit mass $\left(\mathrm{J} \cdot \mathrm{g}^{-1}\right)$

$q^{\prime \prime} \quad$ Heat flux $\left(\mathrm{W} \cdot \mathrm{m}^{-2}\right)$

$T \quad$ Temperature $\left(\mathrm{K}\right.$ or $\left.{ }^{\circ} \mathrm{C}\right)$

\section{Greek}

$\begin{array}{ll}\alpha & \text { Thermal diffusivity }\left(\mathrm{m}^{2} \cdot \mathrm{s}^{-1}\right) \\ \rho & \text { Density }\left(\mathrm{kg} \cdot \mathrm{m}^{-3}\right) \\ \Delta \mathrm{H} & \text { Enthalpy of phase transition }\left(\mathrm{J} \cdot \mathrm{g}^{-1}\right) \\ \Delta x, \Delta t & \text { Space and time steps, respectively }\end{array}$

\section{Subscript}

$\begin{array}{ll}i, n & \text { Pertinent to space }\left(x_{i}=i \cdot \Delta x\right) \text { and time }\left(t_{n}=t_{n-1}+\Delta t_{n}\right) \text { node } \\ l & \text { Liquid } \\ m & \text { Melting } \\ s & \text { Solid }\end{array}$

\section{Superscript}

$p \quad$ Current iteration number 


\section{Introduction}

The light emitting diode is a semiconductor device that converts electrical energy into light as a result of the radiative recombination of carriers (electron and hole) in the $p-n$ junction polarized in the forward direction. LEDs have great potential to replace traditional illumination sources like sodium vapor lamps, incandescent light bulbs or compact fluorescents. This is because of their higher luminous efficacy (20$\left.150 \mathrm{~lm} \cdot \mathrm{W}^{-1}\right)$ than that of incandescent bulbs (10-20 $\left.\mathrm{lm} \cdot \mathrm{W}^{-1}\right)$ [1], small size, slow failure, shock resistance, relatively long useful lifetime of $35000 \mathrm{~h}-50000 \mathrm{~h}$ or more [2]. In addition, LEDs are environment friendly because they do not contain mercury unlike fluorescent lamps. However, on the minus side the initial price of LEDs is high and their performance largely depends on the ambient temperature of the operating environment. An increase in the junction temperature of the LED directly reduces its lifetime as well as its lighting power and photometric flux [3]. As a result, an adequate heat sink is required to maintain its long life. Latent heat storage is considered to be one of the most efficient means for storing thermal energy. Generally, thermal energy can be stored in the form of thermochemical energy (it is absorbed or released by breaking and reforming molecular bonds in a completely reversible reaction), sensible energy (it is stored by changing the temperature of the solid or liquid medium) and latent heat (energy is absorbed or released as a result of reversible phase change occurring in the medium) [4]. Commercial paraffin waxes could constitute a good PCM candidate for a latent heat thermal energy storage system (LHTES). Paraffin waxes meet most of the requirements imposed on LHTES (high thermal energy storage density, good thermal and chemical stability, good self-nucleating properties on freezing, little or no supercooling, lack of phase separation, non-toxicity and reasonable price [5]). Commercial paraffin waxes are cheaper than pure paraffin, they have a moderate latent heat of fusion $\left(L \sim 200 \mathrm{~J} \cdot \mathrm{g}^{-1}\right.$ ) resulting from their high degree of crystallinity, and they have relatively wide range of melting temperatures $\left(22^{\circ} \mathrm{C} \div 68^{\circ} \mathrm{C}\right)$ [6]. On the other hand, their main drawbacks are low thermal conductivity values $(k \sim$ $0.2 \mathrm{~W} \cdot \mathrm{m}^{-1} \cdot \mathrm{K}^{-1}$ ) [6], which may reduce the rate of heat storage, and extraction during the melting/solidification cycles and a potential risk of material ignition. These drawbacks, however, can be limited by using metallic fillers, a finned tube metal matrix [6], nano-silicon dioxide [7] and the application of a fire-barrier-rated container.

Paraffin waxes are made up of a mixture (more than $75 \%$ ) of heavy saturated hydrocarbons called alkanes $\left(\mathrm{C}_{n} \mathrm{H}_{2 n+2}\right)$ where $n$ is in the range 20-40, the rest mostly consisting of iso-alkanes, cyclo-alkanes and alkyl benzene [8]. A comprehensive characterization of alkanes and paraffin waxes for their application in PCM-based energy storage systems was given by Himran et al. [8]. Sharma et al. [9] and Farid et al. [6] presented reviews of phase change energy storage with respect to materials and applications. A review of thermal management systems for electronic components, Li-ion batteries and photovoltaic modules can be found in the paper by Ling et al. [10]. An experimental study on the cooling of portable hand-held electronic devices using PCM ( $n$-eicosane) placed inside heat sinks with and without internal fins was conducted by Fok et al. [11]. Sökmen et al. [3] used ANSYS CFX 14 software to study numerically the effects of fin design, fin material, and free and forced convection on the junction temperature in automotive headlamp cooling applications of LED light. The effect of 
the number of aluminum plate fins $(6,10$ or $3 \times 11$ row fins $)$ separating the layers of PCM (paraffin wax) in designed heat sinks was studied both experimentally and numerically by Kandasamy et al. [12].

It is worth mentioning at this point that although the active cooling technologies of electronic devices based on air driven fans with heat sink assemblies are very efficient, they are expensive and relatively laud. For this reason, currently more and more attention is being paid to active cooling based on piezoelectric fans [13] and synthetic jet impingement [14]. Piezoelectric fans are effective in increasing the turbulence to enhance heat transfer to $375 \%$ with respect to natural convection values. Synthetic jets, in turn, are about three times more effective in cooling than continuous jets at the same Reynolds number. By contrast, passive cooling technologies like liquid cooling or micro-channel cooling are very efficient in removing excessive heat fluxes from electronic devices (up to $1 \mathrm{MW} \cdot \mathrm{m}^{-2}$ ); however, they require a high level of manufacturing to avoid leakage and their implementation is complex and costly. A promising passive cooling system seems to be chemical heat accumulation materials based on granulated open-porous matrix filled with a hygroscopic substance which allow to reach the heat-storing capacity of up to $2000 \mathrm{~J} \cdot \mathrm{g}^{-1}$ [15].

In comparison with the above-mentioned active and passive cooling systems, low cost, compactness, lightness and high efficiency are the main advantages of passive thermal management systems based on PCMs, in particular organic paraffin waxes, which act as a thermal switch by absorbing or releasing latent heat when they undergo a phase change.

The object of this study was an LED panel containing 28 pieces of high-power $1 \mathrm{~W}$ LEDs connected in series (4 LEDs in each of the 7 rows) mounted on an aluminum plate of dimensions $80 \mathrm{~mm}$ by $135 \mathrm{~mm}$ provided by BioSolution. According to the manufacturer of the LED street lamps, the basic user requirement imposed on street lamps is their working time not less than $50000 \mathrm{~h}$ while maintaining a predetermined level of light illumination during their operation. For this purpose, LEDs are fed with pulses of voltage higher than the nominal one. This allows for producing more light and less heat generated in the $p-n$ junction but at the same time causes a higher harmonic distortion of the electric network. The objective of this work was to investigate the extent to which a commercial paraffin wax is suitable for cooling LED lamps.

\section{Experimental}

\subsection{Test Specimens}

Commercial paraffin wax used by Bolsius for manufacturing various kinds of candles was chosen for the tests as PCM. Test specimens for DSC (8.62 mg and $9.24 \mathrm{mg}$ ) and for TG $(12.1 \mathrm{mg})$ were cut off from a tapered white Bolsius candle taken out from a pack purchased in a store ( 10 candles per pack at the price of about $€ 4)$. From the same candle, another sample of material was taken to determine its density at room temperature. Several candles from the same pack were melted in an aluminum vessel to obtain a sample in the form of a cylinder (diameter $6 \mathrm{~cm}$, height $2 \mathrm{~cm}$ ) for testing the thermal conductivity of paraffin wax. This vessel was also used for pouring 
molten paraffin wax inside the hollow compartment of the aluminum block or inside a container made of copper sheet.

\subsection{DSC and TG/DTG Studies}

DSC measurements of the melting $\left(T_{m}\right)$ and solidification $\left(T_{s}\right)$ temperatures and corresponding to them enthalpies of the phase transition during melting $\left(\Delta H_{m}\right)$ and solidification $\left(\Delta H_{S}\right)$ thermal processes as well as temperature characteristics of the apparent specific heat within the range $(-60,+120){ }^{\circ} \mathrm{C}$ were carried out using the Netzsch DSC 214 Polyma thermal analyzer. Thermogravimetric effects were measured using the Netzsch TG 209F3 Tarsus thermal analyzer. Samples weighing $9.24 \mathrm{mg}$ for $c_{p}(T)$ or $8.62 \mathrm{mg}$ for testing thermal effects in PCM and samples of $12.1 \mathrm{mg}$ for TG/DTG were sealed in aluminum pans with a tiny hole punched in their upper lids. The reference pan in each case was an empty sealed one (with a tiny hole). The test specimens were not preheated to $T=90^{\circ} \mathrm{C}$ and maintained for $30 \mathrm{~min}$ before DSC runs, as it had been done in [5] so as not to eliminate the thermal memory effect. Heating and cooling rates $(\mathrm{HR}, \mathrm{CR})$ were $5 \mathrm{~K} \cdot \mathrm{min}^{-1}$ for testing thermal effects and $10 \mathrm{~K} \cdot \mathrm{min}^{-1}$ for testing the apparent specific heat and conducting TG/DTG investigations, respectively. Values of the apparent specific heat were evaluated from the three DSC curves which correspond to: baseline, reference (sapphire) and the sample signals. In order to eliminate the baseline drift, a linear adjustment based on DSC $(t)$ signal values at times $t_{1}$ and $t_{2}$ of the isothermal segments was utilized in accordance with DIN 51007 standard [16] as follows

$$
\operatorname{DSC}_{\operatorname{DIN} 51007}(t)=\operatorname{DSC}\left(t_{1}\right)+\frac{\operatorname{DSC}\left(t_{2}\right)-\operatorname{DSC}\left(t_{1}\right)}{t_{2}-t_{1}}\left(t-t_{1}\right)
$$

The reference material for $c_{p}(T)$ determination was sapphire $\left(\alpha-\mathrm{Al}_{2} \mathrm{O}_{3}\right)$. Nitrogen with a constant volume flow rate of $40 \mathrm{ml} \cdot \mathrm{min}^{-1}$ was used as an inert gas in DSC and TG/DTG studies. Liquid nitrogen was used to perform cooling during DSC studies. Before starting the measurements, temperature and sensitivity calibrations were performed. For the calibration of DSC, the following reference materials of $99.999 \%$ purity were chosen: mercury $(\mathrm{Hg})$, indium $(\mathrm{In})$, tin $(\mathrm{Sn})$, bismuth $(\mathrm{Bi})$, zinc $(\mathrm{Zn})$ and cesium chloride $(\mathrm{CsCl})$, whereas for the calibration of TG/DTG mercury $(\mathrm{Hg})$ was replaced with aluminum $(\mathrm{Al})$ and silver $(\mathrm{Ag})$. The melting temperature and latent heat of fusion of the reference materials used for DSC and TGA calibrations can be found elsewhere $[16,17]$ and therefore are not included here.

\subsection{LED Panel Test}

The study of the LED panel visible in Fig. 1 consisted in temperature measurements taken at a few selected points using K-type thermocouples with the thermoelectrode diameter of $80 \mu \mathrm{m}$. The thermocouples were connected to the NI 9211 card which was inserted into NI cDAQ 9172 chassis. The measuring point TC1 was located on the surface of the LED board which was superimposed with a profiled lid made of acrylic 


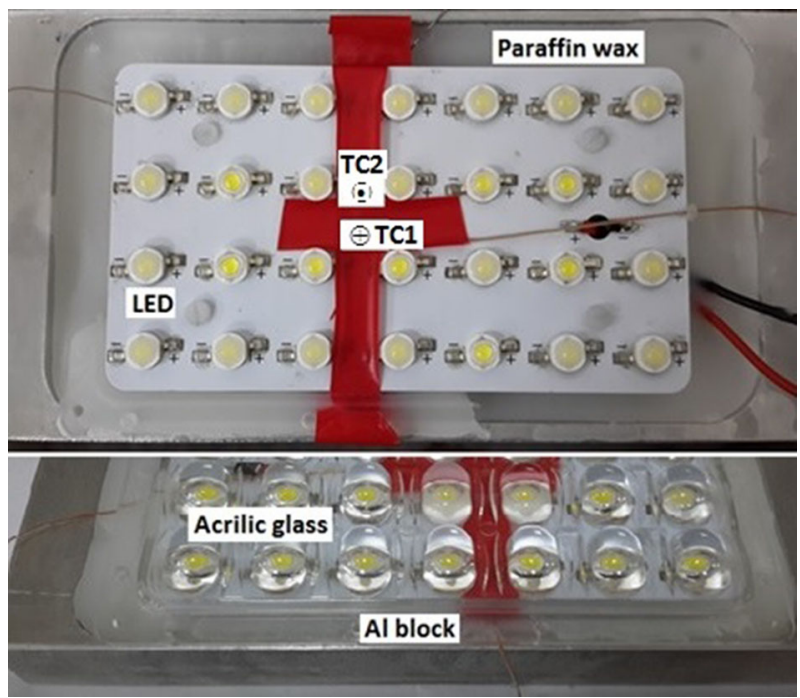

Fig. 1 Object of experimental studies. Panel of LEDs (upper), lid of acrylic glass and Al-block with Bolsius paraffin wax (bottom)

glass and mounted on an aluminum plate $(135 \mathrm{~mm} \times 80 \mathrm{~mm})$. Point TC2 was located on the opposite side of the aluminum plate in the vicinity of paraffin wax which filled up the hollow section of the aluminum block of dimensions $196 \times 100 \times 24(\mathrm{~mm})$. The LED panel was fed by a stabilized DC power supply PPS 2017 for three different power values: $9.3 \mathrm{~W}, 16.6 \mathrm{~W}$ and $28.0 \mathrm{~W}$. Tests were carried out at room temperature or at $50{ }^{\circ} \mathrm{C}$ using a laboratory dryer. A portable precision instrument Almemo 2590 equipped with a heat flux sensor and K-type thermocouples was used to measure the heat flux and temperature of Bolsius paraffin wax abruptly subjected to a heat source maintaining a fixed temperature of $75^{\circ} \mathrm{C}$. Luminance measurements depending on the power supplied and distance from the sensor to the LED panel were performed using a Sonopan L-100 luxmeter.

\section{Results and Discussion}

The results of DSC and TG/DTG investigations are shown in Figs. 2, 3 and 4. DSC studies were carried out within the temperature range $-20{ }^{\circ} \mathrm{C} \div 70^{\circ} \mathrm{C}$ in the following sequences: heating up to $70^{\circ} \mathrm{C}$, cooling down to $-20^{\circ} \mathrm{C}$ and re-heating up to $70^{\circ} \mathrm{C}$. The aim of the second heating was to separate the effect of sample preparation on the occurrence of phase transition temperature. The first minor peak in Fig. 2 at $T=40.9{ }^{\circ} \mathrm{C}$ (first heating), confirmed during second heating at $T=41.5^{\circ} \mathrm{C}$, is attributed to the homogeneously nucleated crystal-rotator transition corresponding to the solid-solid phase transition with onset at $30.4{ }^{\circ} \mathrm{C} / 33.4{ }^{\circ} \mathrm{C}$ for the first/second heating, respectively [18]. This peak is probably related to the reconstruction of the crystal lattice from the orthorhombic to the hexagonal one [19,20] which is typical of some paraffin waxes. The solid-solid transition occurring in Bolsius paraffin wax proves 


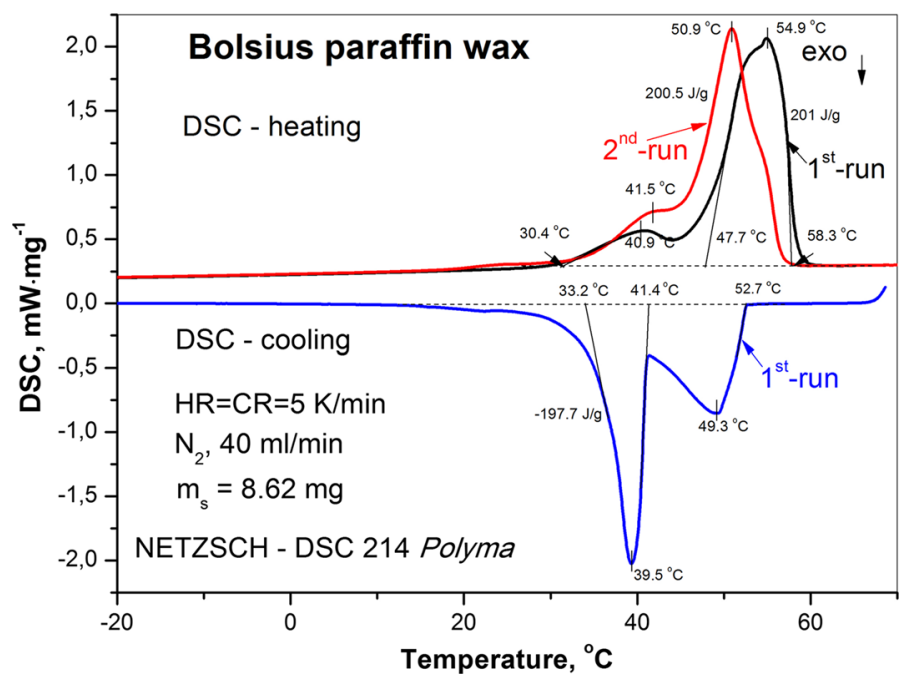

Fig. 2 DSC thermogram of Bolsius paraffin wax

that it involves alkanes with an even number of carbon atoms $(20<n<32)$ [8]. The main endothermic peak at $T=54.9^{\circ} \mathrm{C}$ which was shifted left to $T=50.9^{\circ} \mathrm{C}$ during the second heating can be attributed to heterogeneously nucleated rotator-liquid transition which represents the solid-liquid phase change [18] with end at $58.3 / 56.6{ }^{\circ} \mathrm{C}$, respectively. The latent heat of fusion is $\Delta H_{f}=-201 /-200.5 \mathrm{~J} \cdot \mathrm{g}^{-1}$, its bigger part $\left(-169 /-153.7 \mathrm{~J} \cdot \mathrm{g}^{-1}\right.$ or $\left.84 \% / 76.7 \%\right)$ is the enthalpy of solid-liquid phase change. Peak positions during cooling are shifted with respect to heating due to thermal effects which require additional testing (FT-IR, XRD) for clarification. The extrapolated beginning of the crystallization effect (liquid-solid) is visible at $T=52.7^{\circ} \mathrm{C}$ with peak at $T=49.3^{\circ} \mathrm{C}$. The main peak of solid-solid phase change falls at $T=39.5^{\circ} \mathrm{C}$ with end at $T=33.2{ }^{\circ} \mathrm{C}$. The latent heat of crystallization is $\Delta H_{c}=197.7 \mathrm{~J} \cdot \mathrm{g}^{-1}$. Supercooling is small $\left(5.6^{\circ} \mathrm{C}\right)$, under the cooling rate of $\mathrm{CR}=5$ $\mathrm{K} \cdot \mathrm{min}^{-1}$. To explain the discrepancies between the peaks during the melting and crystallization of paraffin wax visible in Fig. 2, it should be taken into account that during the first heating the thermal contact resistance between the specimen and the aluminum pan is different than during the second heating. This is because upon the completion of the first melting the specimen changes its shape to one that corresponds to the minimum of its free energy. Confirmation of this is an almost identical run of the DSC curves during the first and second cooling (second run of cooling has not been shown in Fig. 2 so as not to obscure the graph view)

Results of TG/DTG investigations of Bolsius paraffin wax are shown in Fig. 3.

Evaporation under $\mathrm{HR}=10 \mathrm{~K} \cdot \mathrm{min}^{-1}$ of Bolsius paraffin wax shown in Fig. 3 proves that its decomposition is a two-step process. In the first step, the highest rate of decomposition $\left(-9.43 \% \cdot \mathrm{min}^{-1}\right)$ is observed at $T=283{ }^{\circ} \mathrm{C}$. In the second step, this effect occurs at $T=323{ }^{\circ} \mathrm{C}$ (decomposition rate $-12.5 \% \cdot \mathrm{min}^{-1}$ ). It follows from this that paraffin wax first evaporates, then it decomposes a little slower at the beginning, and finally the decomposition process is going on slightly faster. 


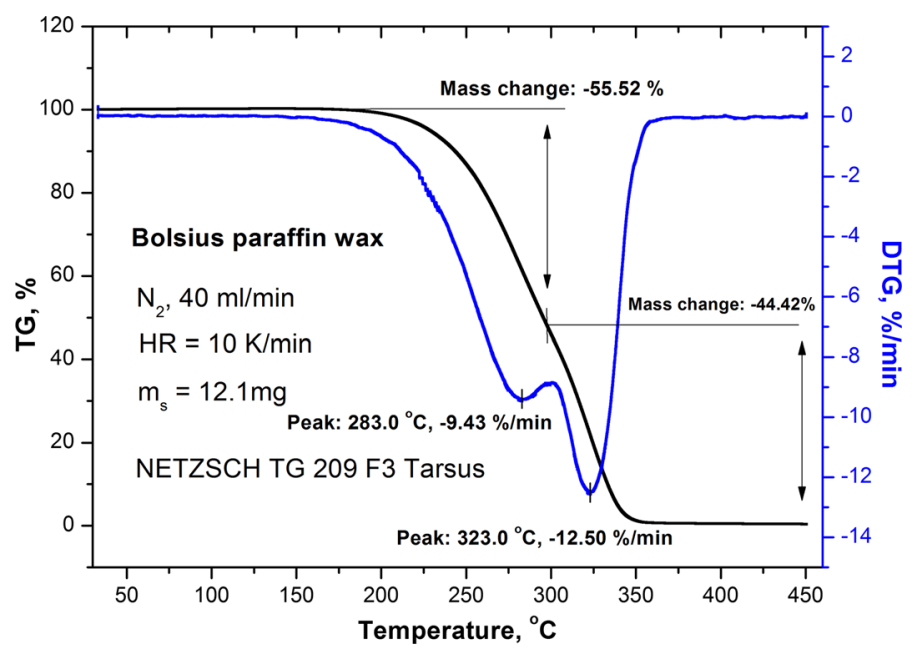

Fig. 3 TG/DTG thermogram of Bolsius paraffin wax

In Fig. 4, the apparent specific heat of Bolsius paraffin wax is presented. This time the heating rate was equal to $10 \mathrm{~K} \cdot \mathrm{min}^{-1}$ so as to comply with the recommended ASTM E1269-11 standard specification. The position of the main peak on $c_{p}$-curve of the solid/liquid phase transition is shifted right by about $2{ }^{\circ} \mathrm{C}$ in relation to DSC results depicted in Fig. 2. The heating rate effect in the tested paraffin wax is connected with the thermal lag between the temperatures of the sample in its center and on its surface resulting from the low thermal conductivity of the sample material. This effect can be reduced (at a fixed HR) by using a smaller sample mass but keeping the representative material structure or by adding certain materials which can improve thermal conductivity. Paper [21] is a good example of an insightful study of the heating/cooling rate effect in PCMs like nanocomposite-enhanced phase-change materials including paraffin.

Figure 5 shows the heat flux, $q^{\prime \prime}$, and normalized temperature histories, $T 1 / T_{\max }$, $T 2 / T_{\max }$, obtained experimentally by a rapid application of a heat source (water cooler) of fixed temperature $T_{\max }=75^{\circ} \mathrm{C}$ to copper container comprising $100 \mathrm{~g}$ of the tested paraffin wax. Here the measuring point TC2 was chosen at the border separating surfaces of the copper container and the water cooler.

Point TC1 was situated $8 \mathrm{~mm}$ from the surface of the heat flow meter which was lying at the bottom surface of the copper container. This experiment confirmed that melting of Bolsius paraffin wax occurs over a temperature range which is characteristic of fully miscible mixtures.

Temperature histories of the LED panel at the measuring point TC2 located on the opposite side of the aluminum plate for various supplied powers are visible in Fig. 6. For heating power of $P=28 \mathrm{~W}$, the assumed value of temperature equal to $60^{\circ} \mathrm{C}$ was reached after $28 \mathrm{~min}$ or after $16 \mathrm{~min}$, respectively, depending on whether the paraffin wax was used or not. Temperature values at the measuring point TC1 located on the surface of the LED panel (cf. Fig. 1) after 30 min were about $15^{\circ} \mathrm{C}$ or $20^{\circ} \mathrm{C}$ higher 


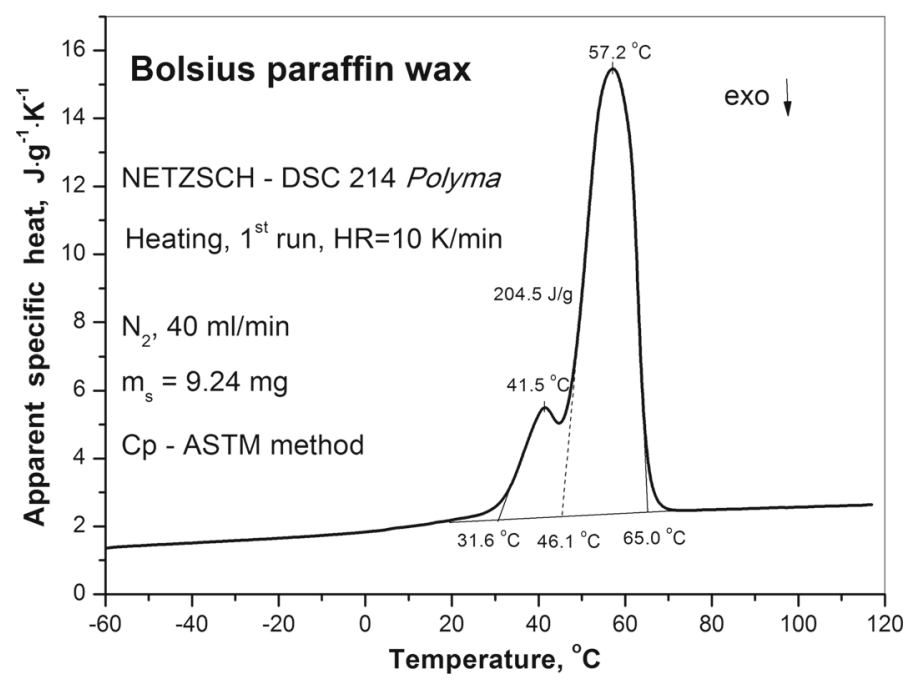

Fig. 4 Apparent specific heat of Bolsius paraffin wax (1st run, $\mathrm{HR}=10 \mathrm{~K} \cdot \mathrm{min}^{-1}$ )

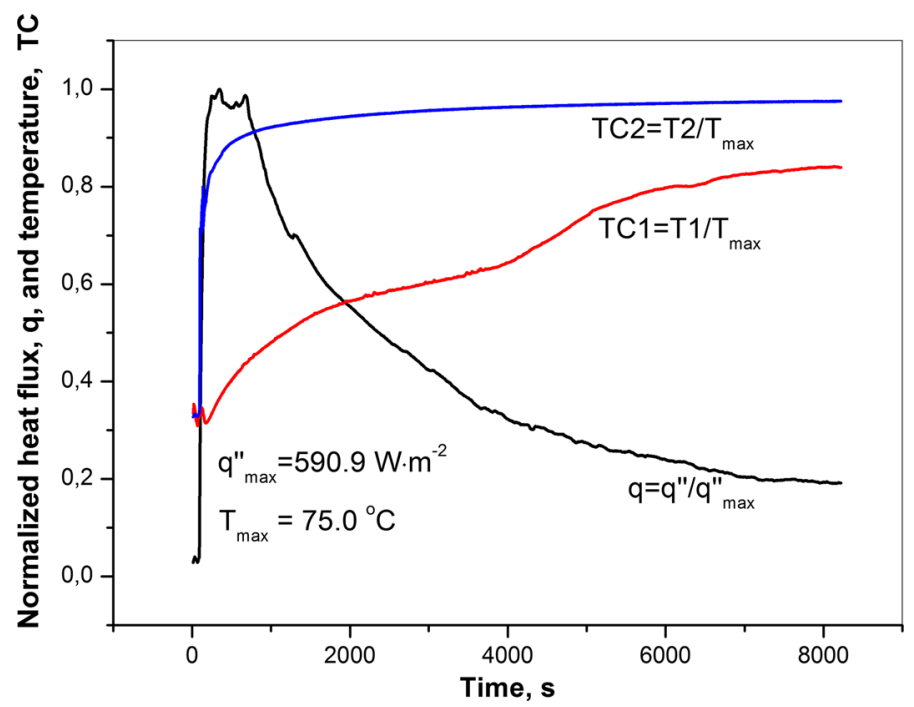

Fig. 5 Heat flux, $q^{\prime \prime}$, and normalized temperature, TC1, histories of Bolsius paraffin wax

than at point TC2, respectively, for $P=16.6 \mathrm{~W}$ or $P=28 \mathrm{~W}$ of heating power when paraffin wax was used. In Fig. 6, the curve marked as "no wax" corresponds to the temperature history measured at point TC1 of the aluminum plate containing 28 LEDs. The plate was placed inside the empty compartment of aluminum block and fitted with an attachment of a four-leg spacer with the leg length of $18 \mathrm{~mm}$ each. Figure 7 presents temperature histories for two measuring points TC1 and TC2 of the LED panel which was put inside a laboratory dryer at controlled temperature of $50^{\circ} \mathrm{C}$. The LED panel was supplied with heating power of $P=9.26 \mathrm{~W}$. Figure 7 shows that after $200 \mathrm{~min}$ 


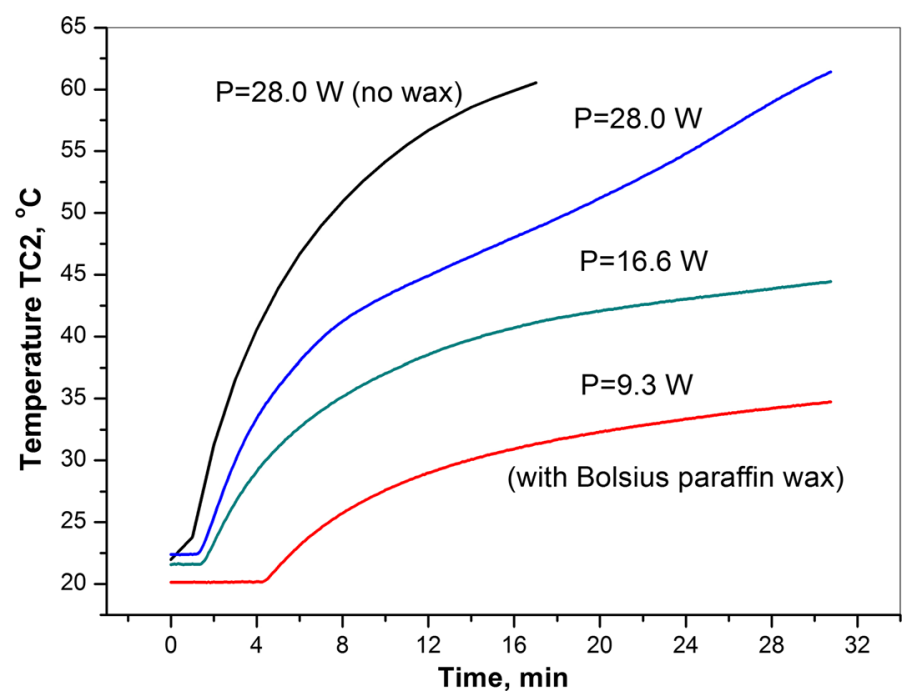

Fig. 6 Temperature histories of LED panel at measuring point TC2 with or without paraffin wax for a few values of supplied heating power

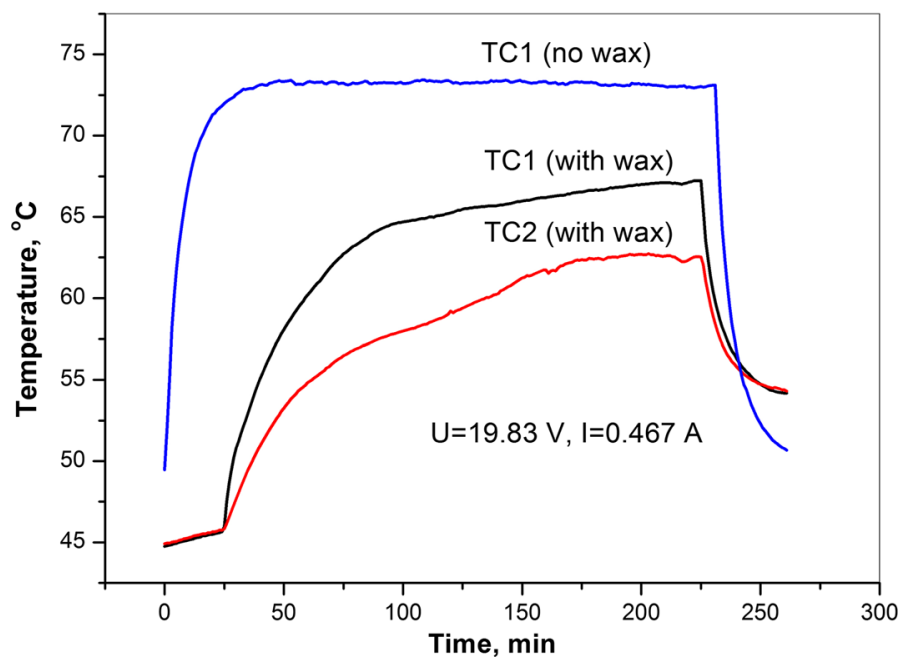

Fig. 7 Temperature histories of LED panel placed inside a laboratory dryer at $50{ }^{\circ} \mathrm{C}$ for two measuring points TC1, TC2 (supplied heating power $\mathrm{P}=9.26 \mathrm{~W}$ )

of continuous heating, the temperature at $\mathrm{TC} 1$ reached about $67^{\circ} \mathrm{C}$ (with wax) and about $72{ }^{\circ} \mathrm{C}$ (without wax), while at point TC2 the temperature reached about $62{ }^{\circ} \mathrm{C}$ (with wax), which proves that the paraffin wax had already melted at point TC2.

Figure 6 shows that Bolsius paraffin wax is molten after several minutes, provided that DC stabilized power supply generates $P=28 \mathrm{~W}$. However, our research has shown that the commercially manufactured street LED lamp containing 56 LEDs fed with current pulses generated by switch mode power supply (SMPS) working at 


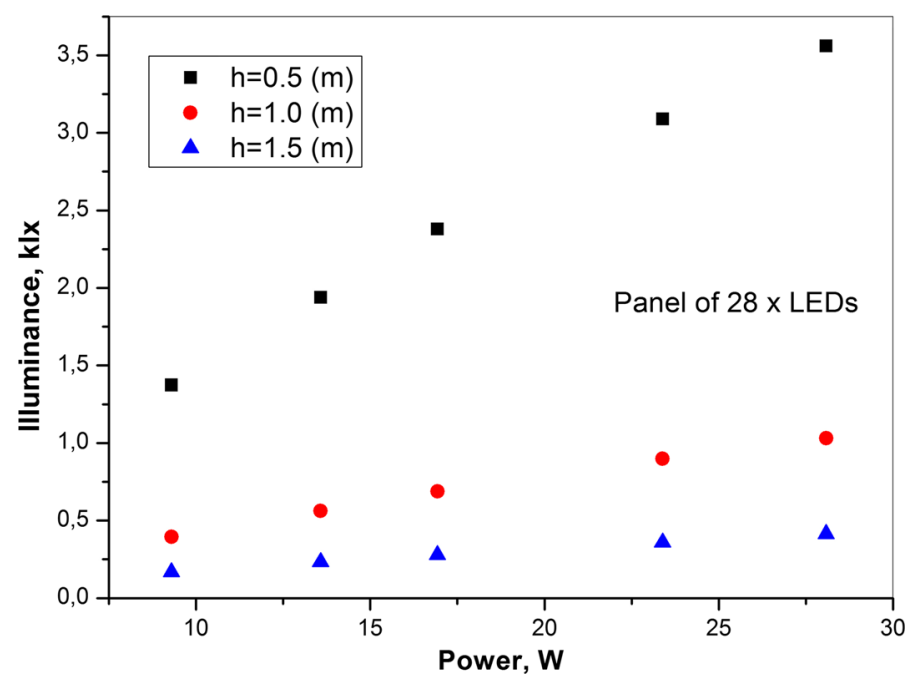

Fig. 8 Experimental results of illumination of LED panel depending on the supplied power and the distance between the light source and the sensor

$f=102 \mathrm{~Hz}$ had an effective power of $P=6.6 \mathrm{~W}$ per one panel consisting of 28 LEDs. The advantage of using PCM in cooling the street LED lamp is visible in Fig. 7 , if we analyze the maximum temperature at point TC1 after $200 \mathrm{~min}$. With the use of DC power supply of $P=9.26 \mathrm{~W}$, the value of maximum temperature amounted to about $66^{\circ} \mathrm{C}$ when PCM was used and $72{ }^{\circ} \mathrm{C}$ without PCM.

The influence of the power supplied to the LED panel being in thermal contact with paraffin wax on its illumination (for three different distances $h$ ) is shown in Fig. 8. In Fig. 8, it is seen that $(i)$ the illumination of the LED panel is almost a linear function of the power supplied to it, ( $i i)$ for the distance of $h=1.5 \mathrm{~m}$ the illumination is smaller than $500 \mathrm{~lx}$ even for $P=28 \mathrm{~W}$. The correlative relationship of illumination dependence $L$ on heating power $P$ at distance $h=1.5 \mathrm{~m}$ takes the following form

$$
L(P)=0.013 P+0.0528, R^{2}=0.9977, L(k l x), P(W)
$$

Figure 9 shows comparison of the temperature measured at point TC2 with that calculated from the solution of 1D two-phase heat transfer model using a fully implicit finite difference method (FDM) based on fix grid with variable time step approach, well described in [22]. Temperature at $x=0$ for time $t_{n}$ can be expressed as (Eq. 3). It was assumed that heat flux $q^{\prime \prime}=q_{0}$ occurs at the surface $x=0$ and convective heat transfer to the surroundings of temperature $T_{\infty}$ takes place with a constant heat transfer coefficient $h$.

$$
T_{0}^{n}=\frac{T_{0}^{n-1}+2 r_{l, n} T_{m}+2 r_{l, n} \Delta x\left(q_{0}+h T_{\infty}\right) / k_{l}}{1+2 r_{l, n}\left(1+h \Delta x / k_{l}\right)}
$$




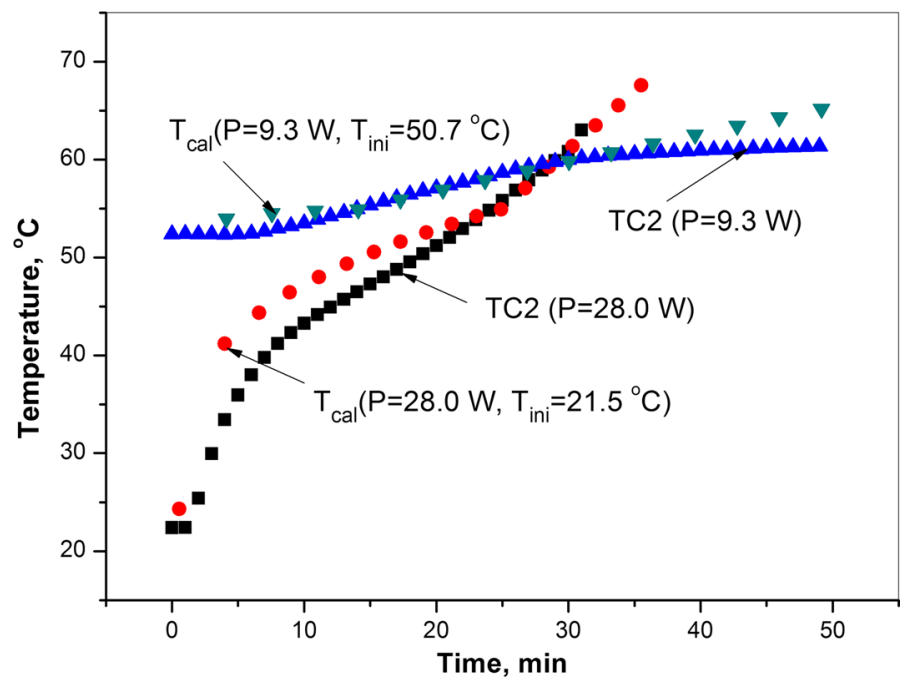

Fig. 9 Comparison of the paraffin temperature measured at point TC2 with that calculated using 1D FDM based on fix grid with variable time step approach

where

$$
r_{l, n}=\alpha_{l} \frac{\Delta t_{n}^{(p)}}{(\Delta x)^{2}}, \Delta t_{n}^{(p)}=\frac{\rho L(\Delta x)^{2} / k_{s}}{T_{n+1}^{n}-\left(1+k_{l} / k_{s}\right) T_{m}+k_{l} / k_{s} T_{n-1}^{n}}, T_{i}^{n}=T\left(i \Delta x, t_{n}\right)
$$

The variable time step $\Delta t_{n}^{(p)}$ at iteration $p$ was chosen in such a way that in the time interval from $t_{n-1}$ to $t_{n}$ the interface moves from the position $(n-1) \Delta x$ to the next position $n \Delta x$. At each time step $t_{n}$, iterations were finished when the following stopping criterion was satisfied

$$
\left|\Delta t_{n}^{(p+1)}-\Delta t_{n}^{(p)}\right| \leq 10^{-9}(s)
$$

Thermal conductivity $k=0.270 \mathrm{~W} \cdot \mathrm{m}^{-1} \cdot \mathrm{K}^{-1}$ of the tested paraffin wax was determined at room temperature using thermal analyzer ISOMET 2104 made by Applied Precision Ltd. The thermal diffusivity was calculated as $\alpha=k /\left(\rho \cdot c_{p}\right)$ where the specific heat $c_{p}$ values were derived from the DSC experiment and accepted for computations in the form $c_{p}(T)=1000(1.8204+0.0077 T) \mathrm{J} \cdot \mathrm{kg}^{-1} \cdot \mathrm{K}^{-1}$ valid for the temperature range $0{ }^{\circ} \mathrm{C} \div 100{ }^{\circ} \mathrm{C}$. Density of the paraffin wax, $\rho=914 \mathrm{~kg} \cdot \mathrm{m}^{-3}$, at room temperature was determined using RADWAG XA/60/220/X analytical laboratory scales of the weighing accuracy $\pm 0.01 / 0.1 \mathrm{mg}$ by triple weighing. The following formula was used $\rho=\left(m_{2} \cdot \rho_{w}\right) /\left(m_{1}+m_{2}-m_{3}\right)$ where $m_{1}$ is the apparent mass of the weight immersed in water, $m_{2}$ is the mass of paraffin wax, $m_{3}$ is the apparent mass of the paraffin wax and the weight in water and $\rho_{w}$ stands for the known density of water. Thermal conductivity, thermal diffusivity and density of solid and liquid phases were accepted for computations as being equal to one another (i.e., $k_{l}=k_{s}$, 
$\alpha_{l}=\alpha_{s}, \rho_{l}=\rho_{s}$ ). The melting temperature was accepted as $T_{m}=54.9{ }^{\circ} \mathrm{C}$ and the ambient temperature as $T_{\infty}=21.4{ }^{\circ} \mathrm{C}$. Heat transfer coefficient was equal to $h=5 \mathrm{Wm}^{-2} \mathrm{~K}^{-1}$, which is a typical value for a free convection. The accepted space step was $\Delta x=0.5 \mathrm{~mm}$. Because of a high temperature gradient at surface $x=0$ caused by heat flux, the initial time step was very small $\Delta t_{1}^{(0)}=10^{-6} \mathrm{~s}$. The results of numerical simulations presented in Fig. 9 are relatively consistent with the experimental ones for up to $50 \mathrm{~min}$. After that time, the discrepancies between the measured and the calculated temperatures were bigger due to the adoption of a too simplified model of heat transfer; hence, the results are not shown here.

\section{Conclusion}

The objective of the undertaken experiments was to investigate a possibility of utilizing a cheap paraffin wax used by Bolsius to manufacture various kinds of candles as a potential PCM for cooling high-power LED lamps. DSC studies of thermal effects revealed a relatively high latent heat of fusion (about $200 \mathrm{~J} \cdot \mathrm{g}^{-1}$ ) of Bolsius paraffin wax which qualifies it as a candidate for a latent heat thermal energy storage systems. However, its limitation is relatively small thermal conductivity (about $0.27 \mathrm{~W} \cdot \mathrm{m}^{-1} \cdot \mathrm{K}^{-1}$ ) which seems to be underestimated in relation to paraffin wax reported by Ukrainczyk et al. [5, Table 1] as equal to $k=0.339 \mathrm{~W} \cdot \mathrm{m}^{-1} \cdot \mathrm{K}^{-1}$ at $T=45.7^{\circ} \mathrm{C}$. It was found that the phase-change transition of the first kind in the tested material of commercial paraffin wax is a two-step process. In the first step, there is a solid-solid phase transition beginning at $T=30.4{ }^{\circ} \mathrm{C}$ which turns in the second step to a solid-liquid phase change with maximum at $T_{m}=54.9^{\circ} \mathrm{C}$ and endset at $58.3^{\circ} \mathrm{C}$.

Results of the experimental studies of temperature histories at the selected measuring points confirmed the usefulness of the commercial paraffin wax as a PCM candidate for cooling LED panels provided that the power supplied to it is less than $28 \mathrm{~W}$. Reducing the power supplied to the LED panel affects its illumination. At the distance of $h=1.5 \mathrm{~m}$, the illumination of LED panel is decreasing by about $33 \%$ when the supplied power changes from $28 \mathrm{~W}$ to $16.6 \mathrm{~W}$.

Numerical modeling of heat transfer with phase-change taking place in commercial paraffin wax, based on the 1D FDM with fix grid using variable time step approach, confirmed its limited applicability but classified it as suitable for engineering practice.

Acknowledgements The authors would like to thank Dr L. Duda and Mr. T. Korablin from Cedar Services Ltd. for providing LED lamps and Dr J. Bareła from the Optoelectonics Institute of MUT for his aid in testing of LED panel illumination. This work was supported by the European Regional Development Fund under the Operational Programme Innovative Economy 2007-2013, POIG.02.02.00-14-022/09. The authors would also like to express their gratitude to the unknown reviewer \#1 for his valuable remarks, which allowed for this paper to be considerably improved.

Open Access This article is distributed under the terms of the Creative Commons Attribution 4.0 International License (http://creativecommons.org/licenses/by/4.0/), which permits unrestricted use, distribution, and reproduction in any medium, provided you give appropriate credit to the original author(s) and the source, provide a link to the Creative Commons license, and indicate if changes were made. 


\section{References}

1. Thermal Challenges In LED Cooling, http://www.electronics-cooling.com/2006/11/thermalchallenges-in-led-cooling/ (active on 1st Sep 2016)

2. Advantages and Disadvantages of LED, http://www.ledke.com/news/Advantages-DisadvantagesLED.html (active on 1st Sep 2016)

3. K.F. Sökmen, E. Yürüklü, N. Yamankaradeniz, Appl. Therm. Eng. 94, 534-542 (2016)

4. J. Banaszek, R. Domański, M. Rebow, F. El-Sagier, Appl. Therm. Eng. 19, 1253-1277 (1999)

5. N. Ukrainczyk, S. Kurajica, J. Šipušić, Chem. Biochem. Eng. Q. 24, 129-137 (2010)

6. M.M. Farid, A.M. Khudhair, S.A.K. Razak, S. Al-Hallaj, Energy Convers. Manag. 45, 1597-1615 (2004)

7. Y. Wang, X. Gao, P. Chen, Z. Huang, T. Xu, Y. Fang, Appl. Therm. Eng. 96, 699-707 (2016)

8. S. Himran, A. Suwono, G.A. Mansoori, Energy Sour. 16, 117-128 (1994)

9. A. Sharma, V.V. Tyagi, C.R. Chen, D. Buddhi, Renew. Sustain. Energy Rev. 13, 318-345 (2009)

10. Z. Ling, Z. Zhang, G. Shi, X. Fang, L. Wang, X. Gao, Y. Fang, T. Xu, S. Wang, X. Liu, Renew. Sustain. Energy Rev. 31, 427-438 (2014)

11. S.C. Fok, W. Shen, F.L. Tan, Int. J. Therm. Sci. 49, 109-117 (2010)

12. R. Kandasamy, X. Wang, A.S. Mujumdar, Appl. Therm. Eng. 28, 1047-1057 (2008)

13. T. Acikalin, S.V. Gorimella, A. Raman, J. Petrovski, Int. J. Heat Fluid Flow 28, 806-820 (2007)

14. A. Pavlova, M. Amitay, J. Heat Transf. 128, 897-907 (2006)

15. E.A. Levitskij, YuI Aristov, M.M. Tokarev, V.N. Parmon, Sol. Energy Mater. Sol. Cells 44, 219-235 (1996)

16. Netzsch Proteus Thermal Analysis, Program manual ver. 6.1 .0 (02.06.2015)

17. R. Sabbah, A. Xu wu, J.S. Chickas, M.L.P. Leitao, M.V. Roux, L.A. Torres, Thermochim. Acta 331, 93-204 (1999)

18. M. Mehrali, S.T. Latibari, M. Mehrali, H.S.C. Metselaar, M. Silakhori, Energy Convers. Manag. 67, 275-282 (2013)

19. A.S. Luyt, I. Krupa, Thermochim. Acta 467, 117-120 (2008)

20. S.Y. Chazhenina, E.N. Kotelnikova, I.V. Filippova, S.K. Filatov, J. Mol. Struct. 647, 243-257 (2003)

21. T.P. Teng, C.C. Yu, Int. J. Chem. Eng. Appl. 3, 340-342 (2012)

22. D.W. Hahn, M.N. Özişik, Heat conduction, 3rd edn. (Wiley, Hoboken, 2012). (Ch.12) 